\title{
Mediación pedagógica y evaluación: Una mirada desde un modelo de marco abierto en educación inicial
}

Pedagogical mediation and evaluation: a look from an open framework model in initial education

\section{Volumen 20, Número 3}

Setiembre - Diciembre

pp. 1-33

Noyle Vargas Muñoz

Cynthia Orozco Castro

\section{Citar este documento según modelo APA}

Vargas Muñoz, Noyle y Orozco Castro, Cynthia. (2020). Mediación pedagógica y evaluación: Una mirada desde un modelo de marco abierto en educación inicial. Revista Actualidades Investigativas en Educación, 20(3), 1-33. Doi. 10.15517/aie.v20i3.43672 


\title{
Mediación pedagógica y evaluación: Una mirada desde un modelo de marco abierto en educación inicial
}

\author{
Pedagogical mediation and evaluation: a look from an open framework model in initial \\ education \\ Noyle Vargas Muñoz ${ }^{1}$ \\ Cynthia Orozco Castro
}

\begin{abstract}
Resumen: El siguiente artículo presenta el proceso de contextualización de la Guía pedagógica para niños y niñas desde el nacimiento y hasta los 4 años del Ministerio de Educación Pública al modelo educativo del Centro infantil laboratorio Ermelinda Mora (CILEM), institución que aplica un modelo de marco abierto. Para obtener la información, se entrevistó a las dos directoras y seis docentes que laboran en la Institución. De igual manera, se realizó un taller de investigación con personas expertas que conocen la trayectoria del Centro Educativo. Con la información suministrada por las participantes, se logró construir un marco filosófico institucional, con el objetivo de adaptar cada uno de los apartados de la Guia pedagógica para niños y niñas desde el nacimiento y hasta los 4 años del MEP al modelo pedagógico de la institución. Como resultado de este proceso, se logró caracterizar los elementos curriculares según el modelo educativo del CILEM. Se reconoce la relevancia del papel docente y de las mediaciones que realiza para llevar a la práctica lo que el modelo establece. Se logró determinar que, en dichos procesos de mediación, lo dispuesto en el ambiente o en el ambiente preparado permite, en las niñas y en los niños, el desarrollo de habilidades para la vida mediante la realización de ejercicios de vida práctica. Esto favorece el rol activo de la niñez en el proceso educativo. Un hallazgo del estudio revela que los procesos de evaluación, en un modelo de marco abierto, incluyen la figura docente en una constante reflexión de lo dispuesto en el ambiente, los materiales o ejercicios que se les presentan a la niñez y el rol de las niñas y los niños. El documento aporta instrumentos de planificación que permiten llevar a la práctica este modelo educativo, además de recomendaciones finales para orientar procesos de mediación pedagógica en un modelo de marco abierto.
\end{abstract}

Palabras clave: mediación pedagógica, evaluación, educación Inicial, modelo de marco abierto

\begin{abstract}
This article presents the process of contextualization of the the Ministry of Education's Pedagogical Guide to Early Childhood from Birth to Age 4, to the open framework educational approach from the Centro Infantil Laboratorio Emerlinda Mora (CILEM). For this research, the two principals and six teachers working for the institution were interviewed. Likewise, a research workshop was held with experts who know the trajectory of this Educational Center. With the information provided by the participants, a philosophical framework was built, with the purpose of adapting the different sections of the Pedagogical Guide to the pedagogical model of the institution. As a result of this process, the curricular components of the guide were characterized according to CILEM's educational model. The relevancy of the role of the teacher, and the facilitation performed, are recognized in order to implement what the model establishes. It was possible to determine that, in such facilitation processes, the setup classroom space and the learning environment itself allow girls and boys to develop life long skills through the engagement on practical everyday life exercises. This favors the active role of children in the educational process. A finding of the study reveals that the evaluation processes, in an open framework model, include the teacher's constant reflection on the classroom setup space, the materials and the activities presented, as well as on the role of the girls and boys. The document provides planning tools to implement this educational model, as well as final recommendations to guide pedagogical facilitation processes in an open framework model.
\end{abstract}

Keywords: pedagogical mediation, evaluation, initial education, open framework model

\footnotetext{
1 Universidad de Costa Rica, Sede de Occidente, Docente en el Centro Infantil Laboratorio Ermelinda Mora; Alajuela, Costa Rica. Dirección electrónica: noyvm19@gmail.com, noilyn.vargas@ucr.ac.cr ORCID: https://orcid.org/0000-0001$\underline{9667-4496}$

2 Docente, Universidad de Costa Rica, Sede de Occidente. Directora académica del Centro Infantil Laboratorio Ermelinda Mora; Alajuela, Costa Rica. Dirección electrónica: cynthia.orozco@ucr.ac.cr ORCID: https://orcid.org/0000-0002-9920-5596
}

Artículo recibido: 15 de junio, 2020

Enviado a corrección: 10 de julio, 2020

Aprobado: 13 de aqosto, 2020 


\section{Introducción}

El Centro Infantil Laboratorio Ermelinda Mora de la Sede de Occidente de la Universidad de Costa Rica tiene más de 40 años de existencia, es un centro pionero, a nivel nacional, en la atención de la primera infancia. Cuenta con un programa de atención para niñas y niños desde los 8 meses y hasta los cuatro años de edad.

Al ser un proyecto que surgió del Departamento de Educación y de la carrera de Educación Preescolar, e integrar los tres ejes sustantivos de la Universidad de Costa Rica, ha existido una larga trayectoria de investigación que ha nutrido, desde diversas perspectivas, el quehacer de la Institución. Esto ha contribuido a que el cuerpo docente haya construido, a lo largo de los años, una actitud proactiva, dialógica y creativa en la búsqueda de propuestas que den respuestas pertinentes a los retos del contexto.

Es necesario mencionar, especialmente, la línea de investigación iniciada por Chavarría, recopilada por Chavarría, Orozco y Vargas en el año 2016, pues dio paso a una construcción conjunta del conocimiento, la cual permitió profundizar el diálogo desde la pedagogía crítica y la deconstrucción del currículo oculto (p. 54). Esta línea de investigación partía de los legados de Freire y Vygotsky como marco referencial, y una perspectiva Montessori-versión holista como acercamiento práctico en torno a la organización curricular.

Con la intención de reflexionar sobre las acciones que se realizan en los salones de clase, se utiliza el ecoanálisis como una metodología para decodificar las prácticas educativas cotidianas. Estas decodificaciones fueron posibles mediante la constitución de equipos docentes de reflexión-acción: primero, en el Centro Infantil Laboratorio de la UCR (CIL); después, en un Centro Infantil de Nutrición y Atención Integral (CINAI) costarricense (Chavarría, Orozco, Chacón y Ovares, 2000; Chavarría y Orozco, 2006a, 2009; y, finalmente, en el Centro Infantil Ermelinda Mora (Carvajal et al., 2015; Chavarría y Orozco, 2006a, 2006b, Chavarría, Obando, Orozco, 2009; Orozco et al., 2014; Orozco, 2007; Vargas et al., 2014, trayectoria que se sintetiza en Chavarría, Orozco y Vargas (2016).

De esta manera, los procesos de investigación citados generaron la posibilidad de hacer múltiples reflexiones sobre el papel de los diferentes actores dentro del proceso educativo, así como la necesidad de sistematizar las experiencias construidas en el CILEM en una propuesta curricular.

Aunado a esto, en el año 2017, el Consejo Superior de Educación aprobó la Guía pedagógica para niños y niñas desde el nacimiento y hasta los 4 años, elaborada por el Ministerio de Educación Pública como documento oficial y de carácter nacional para orientar 
el trabajo con estas edades en el país. El carácter de Guía lo que busca es que pueda ajustarse a la realidad educativa de las instituciones que trabajan con esta población, y el CILEM es una de ellas.

Tanto las conclusiones de investigaciones anteriores, en las cuales se menciona la importancia de propuestas desde un paradigma holista, como la existencia de la Guía pedagógica para niños y niñas desde el nacimiento y hasta los 4 años del MEP resultaron en insumos para justificar la elaboración de este estudio. Surgen de la situación problemática interrogantes, tales como: ¿Cómo atender la ausencia de una propuesta curricular para la atención de niñas y niños de dos a cuatro años de edad en el Centro Infantil Ermelinda Mora, que oriente la mediación pedagógica? ¿Cuál es el papel de la mediación pedagógica al aplicar la Guía pedagógica para niños y niñas desde el nacimiento y hasta los 4 años del MEP al modelo educativo del CILEM? ¿Qué características tiene la metodología que se implementa en el CILEM para la atención de niñas y niños de dos a cuatro años de edad?

Este escenario permitió plantear el objetivo general de elaborar una propuesta curricular para orientar la mediación pedagógica del personal docente que atiende niñas y niños de dos a cuatro años en el CILEM, que se apoye en la amplia experiencia de la institución y que, a la vez, se fundamente en la Guía pedagógica para niños y niñas desde el nacimiento y hasta los 4 años del MEP.

Continuo a este escenario estructural, se plantearon los siguientes objetivos específicos: 1) Caracterizar los elementos curriculares de una propuesta que oriente la mediación pedagógica del personal docente que atiende niñas y niños de dos a cuatro años de edad, según las necesidades, intereses y particularidades requeridas por el CILEM; 2) configurar los elementos curriculares de una propuesta que oriente la mediación pedagógica del personal docente que atiende niñas y niños de dos a cuatro años, a partir de lo propuesto en la Guía pedagógica para niños y niñas desde el nacimiento y hasta los 4 años del MEP, para ser validados por la comunidad educativa del CILEM; 3) diseñar la propuesta curricular para orientar la mediación pedagógica en la atención de niñas y niños de dos a cuatro años de edad del Centro Infantil Laboratorio Ermelinda Mora, a partir de lo propuesto en la Guía pedagógica para niños y niñas desde el nacimiento y hasta los 4 años del MEP, incluyendo los aportes de la comunidad educativa.

Con el alcance de dichos objetivos, se logró elaborar un producto curricular que permita orientar los procesos de mediación pedagógica en el CILEM, desde el modelo educativo empleado. Se logró determinar que un modelo de marco abierto, se lleva a la 
práctica por medio de lo dispuesto en el ambiente preparado. En una visión holista del proceso educativo, es fundamental la actitud crítica, dialógica y participativa del personal docente.

Lo anterior influye de manera sustantiva en los procesos de evaluación que se implementan en la cotidianidad del espacio de aula, orientados a la toma de decisiones de manera oportuna, pertinente e integral.

\section{Referente teórico}

\subsection{Mediación Pedagógica}

La mediación pedagógica hace alusión a la manera cómo las docentes y los docentes propician, potencian y hacen posible el desarrollo de aprendizajes y habilidades en sus estudiantes. El medio utilizado para el logro de aprendizajes y habilidades puede ser: las vivencias y las relaciones que se dan en el espacio de aula, apoyadas en actividades y materiales específicos.

Para Contreras, en la perspectiva de la escuela activa, se reconoce la necesidad de que las estudiantes y los estudiantes tengan un rol activo en el proceso educativo. Por esta razón, el personal docente comenzó a tener un papel menos relevante. Se reconoce la importancia de los aprendizajes de la cotidianidad para la vida; esto permite que las estudiantes y los estudiantes adquieran un papel como protagonistas del proceso educativo, bajo la premisa de que se aprende haciendo (2010, p. 8).

Este concepto de mediación pedagógica hace énfasis en la construcción y elaboración de materiales (por ejemplo, libros de texto) como eje primordial del proceso educativo. En este enfoque no se toma en cuenta la figura docente como sujeto de mediación, su labor es apoyar o programar actividades que respondan a los intereses del estudiantado. Posteriormente, surge el enfoque de reconstrucción del conocimiento. Para Contreras, este enfoque se fundamenta principalmente en tres características: a) Tipos y formas de aprendizaje; b) conocimiento científico, cotidiano y empírico y; hacer y comprender, es decir la relación entre la acción motriz y acción mental (Contreras, 2010, p.10).

De acuerdo con Contreras, la construcción del conocimiento se genera cuando se dan interacciones entre el personal docente y el estudiantado. En este caso, el apoyo docente se considera indispensable para que las estudiantes y los estudiantes se apropien del conocimiento científico que se ha construido a través de la historia, lo que lleva a una actividad mental (2010, p. 14). 
Cabe destacar que un aspecto sobresaliente en el enfoque de reconstrucción del conocimiento es el concepto de aprendizaje significativo.

Para Ausubel, un aprendizaje es significativo cuando se toman en cuenta los conocimientos previos de las estudiantes y los estudiantes; es decir, lo que ya saben o conocen (Ausubel, 1983, p.2). Por esta razón, la labor del personal docente es fundamental para propiciar que los materiales, actividades y recursos que se les presentan al estudiantado contemplen el contexto, que partan de experiencias y vivencias de las niñas y los niños con la intención de posibilitar la construcción de aprendizajes, que les resulten relevantes.

El surgimiento y evolución del concepto de mediación pedagógica resulta fundamental en esta investigación, pues permite identificar, desde el plano conceptual, lo que el término mediar implica, en la práctica educativa, para la atención de niñas y niños de 2 a 4 años, en un centro infantil universitario.

En la tabla 1, se sintetiza el concepto de mediación pedagógica desde diferentes autores y su incidencia en los procesos de mediación pedagógica en el CILEM. 
Tabla 1

Descripción de los paradigmas presentes en el concepto de mediación pedagógica del CILEM
Autor
Concepto de
Metodología de la mediación
Aportes de la

mediación

pedagógica

pedagógica

mediación pedagógica

en la propuesta del

CILEM

\begin{tabular}{|c|c|c|c|}
\hline $\begin{array}{l}\text { Gutiérrez } \\
\text { y Prietto }\end{array}$ & $\begin{array}{l}\text { Estos autores } \\
\text { definen el concepto } \\
\text { de mediación } \\
\text { pedagógica como: } \\
\text { promoción del } \\
\text { aprendizaje desde la } \\
\text { participación, } \\
\text { creatividad, } \\
\text { expresividad, } \\
\text { racionalidad. }\end{array}$ & $\begin{array}{l}\text { Metodológicamente, este concepto } \\
\text { se traduce en el rol activo del } \\
\text { estudiante, estrategias orientadas al } \\
\text { aprendizaje cooperativo, donde unos } \\
\text { aprenden de otros, construcción } \\
\text { constante del conocimiento desde la } \\
\text { libertad en relación con los otros y el } \\
\text { entorno. Presencia de elementos } \\
\text { naturales y culturales en el aula. }\end{array}$ & $\begin{array}{l}\text { Esta definición aporta a } \\
\text { la mediación } \\
\text { pedagógica del CILEM } \\
\text { los conceptos de: } \\
\text { Participación } \\
\text { Creatividad } \\
\text { Expresividad } \\
\text { Relacionalidad } \\
\text { Libertad. }\end{array}$ \\
\hline $\begin{array}{l}\text { Paulo } \\
\text { Freire y la } \\
\text { pedagogía } \\
\text { de la } \\
\text { liberación }\end{array}$ & $\begin{array}{l}\text { Define la mediación } \\
\text { pedagógica como: } \\
\text { Proceso donde la } \\
\text { figura docente } \\
\text { posibilita en la } \\
\text { estudiante o el } \\
\text { estudiante el } \\
\text { desarrollo de la } \\
\text { criticidad, adquisición } \\
\text { de habilidades } \\
\text { intelectuales y } \\
\text { espirituales }\end{array}$ & $\begin{array}{l}\text { Metodológicamente se considera el } \\
\text { rol activo del estudiante con } \\
\text { experiencias encaminadas a la } \\
\text { vivencia de la libertad como medio } \\
\text { para potenciar la capacidad de elegir } \\
\text { y decidir. } \\
\text { Docente como crítico de su práctica } \\
\text { educativa que le lleva a la reflexión } \\
\text { para mejorar. } \\
\text { Opciones varias de trabajo. }\end{array}$ & $\begin{array}{l}\text { Aporta los conceptos } \\
\text { de: Problematización o } \\
\text { reflexión sobre la } \\
\text { practica } \\
\text { Criticidad } \\
\text { Construcción de } \\
\text { conocimiento } \\
\text { Libertad } \\
\text { Características de la } \\
\text { verdadera enseñanza. }\end{array}$ \\
\hline $\begin{array}{l}\text { Lev } \\
\text { Vigotsky }\end{array}$ & $\begin{array}{l}\text { Concepto que incluye } \\
\text { intervenciones entre } \\
\text { el estudiante, la } \\
\text { estudiante y el } \\
\text { contexto social y } \\
\text { cultural con el } \\
\text { lenguaje como } \\
\text { instrumento, figura } \\
\text { docente como apoyo. }\end{array}$ & $\begin{array}{l}\text { La metodología se sustenta en un } \\
\text { acompañamiento temporal para la } \\
\text { construcción del conocimiento, el } \\
\text { apoyo que se retira cuando la } \\
\text { estudiante o el estudiante no lo } \\
\text { necesita. } \\
\text { Busca potenciar el desarrollo } \\
\text { próximo. }\end{array}$ & $\begin{array}{l}\text { Aporta a la propuesta } \\
\text { del CILEM el valor del } \\
\text { concepto social y } \\
\text { cultural } \\
\text { Concepto de } \\
\text { andamiaje } \\
\text { Zona de desarrollo } \\
\text { próximo } \\
\text { Valor del lenguaje como } \\
\text { elemento mediador. }\end{array}$ \\
\hline Holismo & $\begin{array}{l}\text { Mediación } \\
\text { pedagógica como } \\
\text { acciones orientadas } \\
\text { a la construcción del } \\
\text { conocimiento desde } \\
\text { la interconectividad, } \\
\text { en la cual influyen } \\
\text { elementos sociales, } \\
\text { culturales, el } \\
\text { contexto, el entorno. }\end{array}$ & $\begin{array}{l}\text { Metodológicamente se propone rol } \\
\text { activo de la estudiante y el } \\
\text { estudiante desde su integralidad } \\
\text { como persona, reconocimiento del } \\
\text { ambiente social, cultural, natural } \\
\text { como elementos mediadores, } \\
\text { ambientes educativos donde se } \\
\text { tomen en cuenta a través de los } \\
\text { materiales y experiencias. }\end{array}$ & $\begin{array}{l}\text { Entre los principales } \\
\text { aportes a la propuesta } \\
\text { del CILEM están los } \\
\text { conceptos de: } \\
\text { Interconectividad } \\
\text { Integralidad } \\
\text { Comunidad educativa } \\
\text { Respeto a la herencia } \\
\text { cultural y natural. }\end{array}$ \\
\hline
\end{tabular}

Fuente: Vargas (2019), a partir de Castillo y Castillo, (2016). 


\subsection{Mediación pedagógica desde un modelo de marco abierto}

La mediación pedagógica que se realiza dentro del proceso educativo responde a un concepto de currículo, paradigma y enfoque curricular. El papel docente gira en torno a propiciar aprendizajes desde lo que está establecido, en cada caso particular, a través de los planes y programas que se implementan por medio de la metodología que orienta el proceso. En este contexto, se describe el modelo de marco abierto.

Chavarría y Pérez, en el año 1995, realizaron una investigación en la cual se observaron múltiples centros infantiles del país, se registraron minuciosamente los aspectos cualitativos observados, luego se realizó una cuantificación. En esta investigación, destacaba, factorialmente, el centro infantil montessoriano "no ortodoxo", el cual reflejaba una cosmovisión alternativa, con una novedosa incorporación de la cotidianidad, la educación para la vida, en la vida, con la vida, propios de un modelo de marco abierto.

El modelo de marco abierto se caracteriza por la combinación entre la iniciativa de los niños, de las niñas y de las personas adultas. Para Chavarría y Pérez, este modelo: "Parte de la convicción de que es importante la contribución del profesor, con su bagaje de conocimientos y su posición específica como mediador de la cultura general; asimismo es importante el respeto por la actividad del niño" (1995, p.28).

Los sistemas de trabajo que aplican un modelo de marco abierto potencian, en las niñas y en los niños, la posibilidad de contar con ambientes de aprendizaje enriquecidos. La diversidad de material se da por el aporte que las docentes y los docentes hacen al estar atentas y atentos a las características de sus estudiantes. En estos modelos, según Chavarría y Pérez, los adultos proponen el desarrollo de las capacidades de los niños y las niñas, al darles la posibilidad de que puedan razonar y establecer relaciones entre sus acciones y lo que sucede en su entorno cercano. De esta manera, los infantes y las infantes tienen libertad para elegir y el adulto acompaña (Chavarría y Pérez, 1995, p. 28).

Es importante que el personal docente tenga claridad de los procesos de desarrollo de las niñas y de los niños que atienden, con la finalidad de proponer experiencias según su nivel evolutivo y propiciar el salto a experiencias más complejas, esto, con el objetivo de potenciar nuevos niveles de integración en todas las áreas, y el desarrollo de habilidades prosociales, como la empatía.

Desde un modelo de marco abierto, los procesos de mediación pedagógica se caracterizan por la persona adulta, quien ofrece lo dispuesto en el ambiente, con el propósito de que los niños y las niñas exploren con libertad, experimenten y construyan aprendizajes. 
El adulto es parte del ambiente, acompaña, realiza andamiajes, guía, orienta el proceso y media entre los aspectos relevantes de la cultura y el mundo infantil.

Cabe destacar, en este sentido, los aportes que realizan autoras como Peralta y Fujimoto, quienes han rescatado la necesidad de que los currículos para la atención de la primera infancia tengan el componente cultural como un ingrediente que añade significado a las experiencias que se le presentan a la niñez. Los aportes de la familia y de la comunidad son sumamente necesarios para atender las necesidades de las niñas y los niños. Señalan además que: ..."existe también la necesidad de buscar el nexo entre los niños y su realidad en la práctica pedagógica, para abordar los programas con grupos poblacionales como personas plenas, desde su propio estilo de vida, respetando la manera de ser" (Peralta y Fujimoto, 1998, p. 130).

\subsection{Mediación pedagógica y ambiente preparado}

Los procesos de mediación pedagógica responden a la metodología empleada, la cual constituye el medio por el que el modelo educativo se lleva a la práctica, esto influye directamente en las interacciones que se dan entre docentes y estudiantes.

El modelo de marco abierto se apoya en un ambiente preparado, concepto acuñado por Montessori en su metodología y en su visión de profundo respeto por el quehacer de las niñas y los niños, y busca precisamente favorecer la exploración como una manera de establecer puentes entre el mundo real y el mundo de las niñas y de los niños.

El personal docente, con una actitud de observación, criticidad y reflexión, propone lo dispuesto en el ambiente físico para propiciar interacciones entre las niñas y los niños, que les llevarán a la construcción del aprendizaje.

Cuando se establecen puentes entre los niños, las niñas y la cultura se posibilita la construcción de conocimientos de manera significativa. Al respecto, Rodríguez señala: "El aprendizaje implica la apropiación y el dominio de instrumentos culturales disponibles en nuestro medio" (2010, p. 5).

La mediación docente siempre pone la cultura a disposición de la niñez. El uso de herramientas socioculturales, tales como el lenguaje, el uso del espacio y los actos cotidianos, en general, dan sentido a la mediación sociocultural que realizan las docentes y los docentes.

De acuerdo con Montessori Jr, "el medio ambiente preparado debe colocar el mundo, y por lo tanto el mundo adulto, al alcance del niño en cualquier etapa del desarrollo en que 
este se encuentre en un momento dado" (1991, p.39). La expresión del autor permite ver cómo se debe favorecer la accesibilidad en las niñas y los niños. Es decir, el ambiente que se crea en el espacio de aula debe favorecer que las infantes y los infantes se desenvuelva con auto gestión.

Por esa razón, la mediación pedagógica es fundamental para lograr detectar las carencias de la niñez y realizar los ajustes pertinentes de acuerdo con sus necesidades

Es importante señalar, tal y como lo menciona Montessori, que el ambiente preparado debe cumplir con tres características indispensables: la primera es que debe ser atractivo, estético y práctico, pero también reflejar orden y organización. La segunda es que debe favorecer el interés de las niñas y de los niños en las actividades que se les presentan. La tercera es que el ambiente preparado debe fomentar que cada niña o niño pueda realizar las actividades a su propio modo y ritmo.

El ambiente preparado debe derivarse, no del deseo del adulto por imponer su autoridad, sino de permitir a todo individuo libertad de actividad independiente, en tanto su libertad no interfiera con la de los demás (Montessori, 1991, p.39).

Entre las actividades que se proponen, con la intención de favorecer la libertad de elección, están las de vida práctica, las cuales forman parte del ambiente preparado y buscan que las niñas y los niños vivencien situaciones de su cotidianidad.

Las tareas de vida práctica corresponden exactamente lo que los niños buscan a esta edad: una actividad que requiere de su energía muscular y que puede producir resultados visibles que sean útiles para ellos mismos y las personas que viven con ellos. (Quattrocchi, 1999, p. 170)

En este sentido, tal y como lo presenta la autora, cuando las niñas y los niños logran, por ejemplo, vestirse sin ayuda, preparar alimentos, servir la mesa, se están desarrollando en habilidades para la vida, que les brindarán autogestión, además del desarrollo cognitivo y social.

Los ambientes diseñados con la intención de ofrecer múltiples opciones de trabajo a las niñas y niños favorecen el desarrollo de habilidades para la vida, aprecio por el entorno natural y sociocultural; con el lenguaje como herramienta cultural, que, además posibilita interacciones entre los miembros del grupo.

El papel de la persona adulta, es el de guiar, acompañar a las niñas y a los niños en la construcción de los conocimientos y reflexionar acerca de su práctica educativa. Por esta 
razón, observa de manera constante el desempeño de los infantes y las infantes con el objetivo de propiciar experiencias enriquecedoras que favorezcan el rol protagónico de la niñez.

En ambientes con variedad de opciones para las niñas y niños, en los cuales se contemplan el ambiente preparado y actividades de la vida cotidiana, el concepto de mediación pedagógica es todo lo opuesto a transmitir. La persona que media propicia, ofrece, propone y, desde esa perspectiva, el que "aprende" se involucra desde una posición diferente a la de simple receptor. Un aspecto fundamental en este concepto hace alusión a que el rol protagónico de las niñas y los niños está dado por la figura docente, quien posibilita el papel activo de la niñez por medio de las mediaciones que realiza.

Con base en lo descrito, se puede definir el concepto de mediación pedagógica en el CILEM como todas y cada una de las acciones que realiza el personal docente, con la finalidad de posibilitar que las niñas y los niños puedan construir conocimientos en un ambiente de flexibilidad y libertad que posibilite la indagación, la experimentación, el gozo.

\subsection{Marco normativo de la propuesta}

Dentro del marco normativo, un aspecto fundamental que motivó la creación de este estudio lo constituye la publicación de la Guía pedagógica para niñas y niños desde el nacimiento y hasta los 4 años del Ministerio de Educación Pública, aprobada por el Consejo Superior de Educación en el año 2017. En Costa Rica, las propuestas educativas se sustentan en lo dispuesto por la Constitución Política y la Ley Fundamental de Educación en un nivel general. Por tratarse de una propuesta para la primera infancia, se debe ser respetuoso de los lineamientos establecidos por el Patronato Nacional de la Infancia, el Código de la Niñez y la Adolescencia y demás instituciones que tienen que ver con el tema de la niñez en Costa Rica.

Esta Guía es el documento oficial para trabajar con estas edades, la cual constituye el marco de referencia para todas las ofertas de atención que existen en el país para el trabajo con niñas y niños desde el nacimiento y hasta los 4 años. En este documento se recoge la visión país del proceso educativo, pues se nutre de la Política Curricular Educar para una Nueva Ciudadanía y la Política Educativa La persona: centro del proceso educativo y sujeto transformador de la sociedad.

El marco normativo, citado constituyó la justificación y viabilidad del estudio que permitió adaptar un documento de carácter oficial a un proyecto educativo de centro. 


\section{Metodología}

Los temas tratados en este apartado permiten establecer relaciones entre el marco teórico de la investigación y el trabajo de campo realizado. Es una descripción de los procedimientos que se siguieron para lograr aplicar en método científico con enfoque intersubjetivo.

\subsection{Enfoque}

El estudio fue de carácter cualitativo, ya que valoró las intersubjetividades del discurso y las experiencias de vida de las docentes y las autoridades en la Institución, y también de carácter descriptivo, ya que logró una caracterización de la situación de aprendizaje en el aula y su relación con los lineamientos de la Guía pedagógica para niñas y niños desde el nacimiento y hasta los 4 años del MEP.

La investigación estuvo enmarcada dentro del paradigma fenomenológico, pues buscó la comprensión del discurso de las personas que suministran la información durante el proceso. Se planteó la necesidad de realizar una sistematización de las acciones que las docentes del CILEM realizan en el espacio de aula, en su ambiente natural, en sus experiencias. La periodicidad del proceso de recolección de la información fue de tipo transaccional o transversal, se realizó en un momento determinado concentrado en el segundo semestre del año 2018.

\subsection{Unidad de análisis}

Dentro del proceso de investigación, la unidad de análisis estuvo constituida por las docentes contratadas por la Universidad de Costa Rica que tienen título de educación preescolar, con más de un año de trabajar en el CILEM. Las participantes debían suministrar la información que se requirió desde su posición y relación con el objeto de estudio. 
Tabla 2

Participantes del proceso de investigación en el CILEM

Participantes

Directora Criterios de inclusión

administrativa

Mujer que tiene un título en Ciencias de la Educación Preescolar

Ha laborado por más de 10 años como docente de educación preescolar, con experiencia en mediación pedagógica para la atención de niños y niñas de dos a cuatro años.

Encargada de la revisión de planeamientos didácticos en la institución.

\section{Directora}

académica

Mujer que tiene un título en psicología, que tiene experiencia en investigación sobre metodologías pertinentes para orientar la mediación pedagógica en niños y niñas menores de cuatro años.

Investigadora del IIP de la Universidad de Costa Rica, directora y lectora de tesis realizadas en el CILEM y de las cuales han provenido los insumos que orientan las acciones educativas.

Docente de la carrera de Educación inicial en la Sede de Occidente, encargada del proyecto ante Acción Social de la Sede de Occidente.

Docentes: 8 Encargadas de la atención de las niñas y los niños en el CILEM.

Orientadoras de las niñas y los niños en el proceso educativo y que cuentan con título en, Ciencias de la Educación Preescolar con más de 1 año de experiencia en la atención de niñas y niños de dos a cuatro años, en el CILEM.

Especialista en el tema

Profesional en psicología, propulsora en el país de metodologías pertinentes para el trabajo con niñas y niños de dos a cuatro años.

Directora de tesis realizadas en el CILEM, autora de varios artículos sobre el tema.

Fuente: Vargas (2019, p.64).

Es importante señalar que para realizar la investigación se contó con la aprobación de la Dirección del CILEM y cada una de las participantes conoció el plan de garantía ética y completó el consentimiento informado como principio de confidencialidad y no maleficencia de la investigación.

El periodo de análisis de la información se desarrolló en el primer semestre del año 2019, logrando un proceso de transcripción, categorización de la información y representación de los análisis obtenidos por fuente.

\subsection{Técnicas de recolección de información}

Para obtener la información, se consideró oportuno la utilización de los siguientes instrumentos: entrevista semi estructurada, taller de investigación. 


\subsubsection{Entrevista semi estructurada}

Con la entrevista semi estructurada se indagaron los tres principales constructos: importancia de la educación y atención en la primera infancia, marco curricular y mediación pedagógica. A partir de los constructos, se seleccionaron las categorías y finalmente se elaboraron las preguntas por categoría y por fuente.

Las entrevistas contemplaron aspectos que favorecieran la construcción de la propuesta curricular. Se ahondó también en el modelo educativo del CILEM para construir un concepto de mediación pedagógico coherente con el trabajo que se realiza en la Institución. Se consideró también el criterio de las directoras para indagar sobre las articulaciones que, desde lo administrativo y lo pedagógico, deben hacerse en la Guía adaptada al CILEM para orientar los procesos.

\subsubsection{Taller de investigación}

Este fue un instrumento utilizado para garantizar que se obtuvieran la información confiable y fiel a la historia de los hechos observados en el estudio. Consistió en una reconstrucción de la historia del CILEM sobre los tres principales constructos que conformaron parte de esta investigación (Atención en la primera infancia - Mediación pedagógica - Cambios observados en la institución a nivel curricular).

Los insumos obtenidos al utilizar este instrumento fueron de gran aporte como un medio para justificar la pertinencia de este estudio.

\subsection{Procesamiento de análisis}

La información recopilada tuvo un tratamiento de tipo analítico, donde el discurso de las participantes se procesó desde un enfoque de interpretación por agrupación de categorías, lo que permitió un proceso de decodificación abierta, donde se analizaron categorías previas y emergentes. A continuación, se exponen los pasos utilizados en el procesamiento del análisis.

\subsubsection{Análisis por reducción de la información}

Fue una técnica que permitió la decodificación de la información, donde a cada expresión emitida por cada una de las participantes del estudio se le asignó un código.

Para Álvarez Gayou: "Se codifica cuando se traduce a un sistema secreto de símbolos...también se codifica cuando se utilizan contracciones para representar otras 
palabras más complejas" (2003, p.95). Por tanto, cuando se analizó la información de las categorías apriorísticas o emergentes para la elaboración de la propuesta curricular, el proceso de codificación aportó en la confirmación de los usos lingüísticos institucionales.

\subsubsection{Análisis por agrupación de la información}

Este aspecto hace referencia a agrupar la información por familias conceptuales según su vínculo y relación. En el estudio, una vez que se hizo el proceso de reducción de la información, se procedió a agruparla por similitud de vínculo o relación, permitiendo identificar familias conceptuales.

\subsubsection{Representación de la información}

El resultado del análisis de cada fuente se representó de cuatro formas diferentes, la primera permitió ilustrar el principio de saturación de la información a través de gráficas nominales que permitieron observar las frecuencias del discurso en las diferentes categorías de análisis.

El segundo tipo de representación fueron gráficas solares, que recoge la agrupación de categorías en familias conceptuales, logrando identificar categorías emergentes.

Un tercer tipo de representación de la información fueron los cuadros dinámicos descriptivos, que permitieron recoger el discurso de las participantes para darle sustento a la saturación de la información desde la expresión de primera fuente, destacando la identificación de categorías de análisis, la expresión emitida por las participantes y la identificación del sujeto de estudio a través de una expresión codificada, para guardar el principio de confidencialidad.

Una cuarta forma de representar los resultados fueron las ilustraciones donde se sintetiza la información analizada. Esta última fue la que predominó en el análisis para elaborar la propuesta del CILEM a partir de la Guía pedagógica para niños y niñas desde el nacimiento y hasta los 4 años del MEP.

\subsubsection{Triangulación}

La triangulación relacionó la teoría fundada con la información suministrada por cada una de las fuentes. En cada categoría se analizaron las fuentes por separado (las docentes, las directoras y personas expertas en el tema). Cada fuente permitió información particular, por lo cual, la triangulación concatenó los diferentes discursos y su vinculación con la teoría. 


\section{Resultados}

Los resultados del estudio permitieron dar respuesta a los objetivos específicos que estuvieron orientados a: 1) La caracterización de los elementos curriculares; 2) configurar los elementos curriculares y; 3) diseñar la propuesta curricular para orientar la mediación pedagógica del CILEM.

\subsection{Alcance de los objetivos de investigación}

Objetivo 1: Caracterizar los elementos curriculares de una propuesta que oriente la mediación pedagógica del personal docente que atiende niños y niñas de 2 a 4 años según las necesidades intereses y particularidades requeridas por el CILEM.

Cabe destacar que para lograr este objetivo se elaboraron categorías que suministraran la información que permitiera caracterizar los elementos curriculares.

En este sentido, se pudo materializar, al indagar con los participantes del estudio sobre cómo se percibe desde la realidad del CILEM cada uno de estos aspectos: a) rol de la niña y el niño en el espacio de aula; b) concepto de atención integral; c) necesidades afectivas en niñas y niños de dos a cuatro años; d) competencias personales y profesionales del personal docente; e) aprendizajes por construir; f) definición de currículo; g) rol de la niña y el niño en la planificación; h) papel del contexto en la planificación; i) papel de la infraestructura.

Es así como se logra determinar que la relación docente- niñez en el CILEM está determinada, en gran medida, por una concepción del papel docente como guía del aprendizaje. Destaca, también, el compromiso profesional de tener un ambiente preparado, parte indispensable dentro de una metodología de trabajo caracterizada por la participación activa de la niñez.

La mediación pedagógica en el CILEM responde a un modelo metodológico en el cual cobran relevancia elementos como la importancia del ambiente preparado, la zona de desarrollo próximo, andamiaje, donde las docentes por medio de su comportamiento y el modelaje del uso del material guían a las niñas y los niños en el proceso educativo. Estos elementos son, además, muy acordes con los conceptos teóricos y metodológicos discutidos y vivenciados en investigaciones anteriores llevados a cabo en la Institución y ampliamente discutidos en el Equipo Técnico de la institución.

En la sesión con personas expertas, se logró determinar el cambio histórico que ha habido en el CILEM en el rol docente, una mayor reflexión del papel como mediadoras y 
facilitadoras, que demuestra la importancia de generar espacios de discusión sobre las prácticas educativas que tienden a naturalizarse.

Un reto que se observaba para las docentes participantes, era el poder conciliar la riqueza de las experiencias acumuladas en la institución, los cambios en la planificación y la directriz de aplicar la Guía pedagógica para niños y niñas desde el nacimiento y hasta los 4 años del MEP. Esta coyuntura, aunada a la amplia discusión de vivencias y conceptos planteados en el marco filosófico y epistemológico de las investigaciones anteriores, les permitió a las docentes construir un bagaje que se sistematiza en esta investigación, generando los insumos necesarios para caracterizar los elementos, fundamentos, fuentes y elementos curriculares dando respuesta al objetivo 1.

La sistematización anterior permitió obtener información valiosa para la construcción de un marco filosófico y pedagógico específico del CILEM. Esto facilitará que las docentes comprendan la teoría que orienta a la institución en la atención de las niñas y niños de 2 a 4 años para clarificar los procesos de mediación docente desde un modelo de marco abierto.

Objetivo 2: Configurar los elementos curriculares de una propuesta que oriente la mediación pedagógica del personal docente que atiende niñas y niños de dos a cuatro años, a partir de lo propuesto en la Guía pedagógica para niños y niñas desde el nacimiento y hasta los cuatro 4 de edad, para ser validados por la comunidad educativa del CILEM.

Para alcanzar este objetivo se analizaron las siguientes categorías: a) estrategias pertinentes para promover el desarrollo integral; b) papel docente; c) actividades para favorecer el desarrollo integral de las niñas y niños de 2 a 4 años; d) papel de la familia en la planificación docente; e) papel del ambiente natural en la planificación; las cuales, al indagar con las informantes, permitieran configurar los elementos curriculares para orientar los procesos de mediación pedagógica.

Es así como se constata que en el CILEM hay claridad de las estrategias que potencian el desarrollo integral, se rescata la importancia del desarrollo de habilidades para la vida, lo que tiene que ver con proactividad, libertad de elección, desarrollo de la afectividad, la comunicación asertiva.

EI marco filosófico del CILEM le diferencia de otras instituciones, principalmente por la metodología empleada, donde el ambiente preparado, el papel docente y el rol de las niñas y los niños, favorecen el desarrollo de habilidades para la vida.

Las docentes del CILEM que participaron del estudio tienen claridad de su papel de guías y mediadoras con el entorno natural y sociocultural, y en la construcción de 
aprendizajes en las niñas y los niños, reconocen la necesidad de reflexionar de manera sistemática y constante acerca del accionar en el aula como parte del trabajo que realizan.

En el modelo educativo que se aplica en la institución, las familias ocupan un espacio importante. Esto debido a que realizan aportes en los diferentes temas que se trabajan a lo interno de los salones de clases, ya sea desde su área de experticia o desde sus experiencias de vida.

Con la información suministrada se lograron conformar objetivos, contenidos, estrategias de aprendizaje y actividades de la propuesta curricular, y de esta manera elaborar el producto curricular acorde con las particularidades del CILEM, cuya validación fue dada por la comunidad educativa.

Objetivo 3: Diseñar la propuesta curricular para orientar la mediación pedagógica en la atención de niños y niñas de 2 a 4 años del Centro Infantil Ermelinda Mora a partir de lo propuesto en la Guía pedagógica para niños y niñas desde el nacimiento y hasta los 4 años del MEP, incluyendo los aportes de la comunidad educativa.

Para alcanzar este objetivo, resultó indispensable recabar información de primera fuente, es decir desde los testimonios de las participantes acerca de los procesos educativos y de sus experiencias de vida; esta información generó insumos para elaborar la propuesta curricular para ser validada por la comunidad educativa.

Debido al nivel de concreción de este objetivo, donde lo que se requería era establecer con mucha claridad los elementos que conforman la propuesta, se incluyó las categorías que suministraran información relevante acerca de los elementos curriculares. Cada una de las categorías corresponde a un apartado de la propuesta.

Como resultado, se pudo constatar que el diseño de la propuesta curricular para orientar la mediación pedagógica del CILEM debía contemplar los siguientes aspectos: a) El CILEM es un Centro Infantil Universitario. b) La importancia del contexto socio cultural y natural. c) El enfoque socio constructivista. d) Papel docente fundamental como mediadora de la cultura, guía, reflexiva de su práctica. e) Ecoanálisis como herramienta de decodificación para determinar por medio de la observación el porqué de lo dispuesto en el ambiente. f) Rol activo de las niñas y los niños. g) Modelo de marco abierto y holismo en la educación inicial. h) El ambiente preparado y ejercicios de vida práctica como medios para el desarrollo de habilidades para la vida.

Cada uno de los aspectos mencionados es un referente del marco filosófico del CILEM y se evidencian en la propuesta curricular. 
El logro de este objetivo permitió elaborar la Guía pedagógica para niñas y niños de 2 a 4 años de edad en el CILEM. Este documento consta de los siguientes apartados: 1) Presentación. 2) Tabla de contenidos. 3) Introducción. 4) Glosario donde se clarifican términos que permiten una mejor comprensión de los procesos de mediación pedagógica desde un modelo de marco abierto. 5) Propósito de la guía. 6) El marco normativo. 7) Marco pedagógico, el cual define: Concepto de currículo, Elementos curriculares, Fuentes curriculares, fundamentos curriculares desde el enfoque socio constructivista y el modelo del CILEM. 8) Orientaciones específicas. 9) Organización y descripción de los ámbitos de aprendizaje.

Figura 1

Portada de la guía pedagógica para niñas y niños de 2 a 4 años de edad, adaptada a las directrices del Ministerio de Educación Pública

Fuente: Vargas (2019).

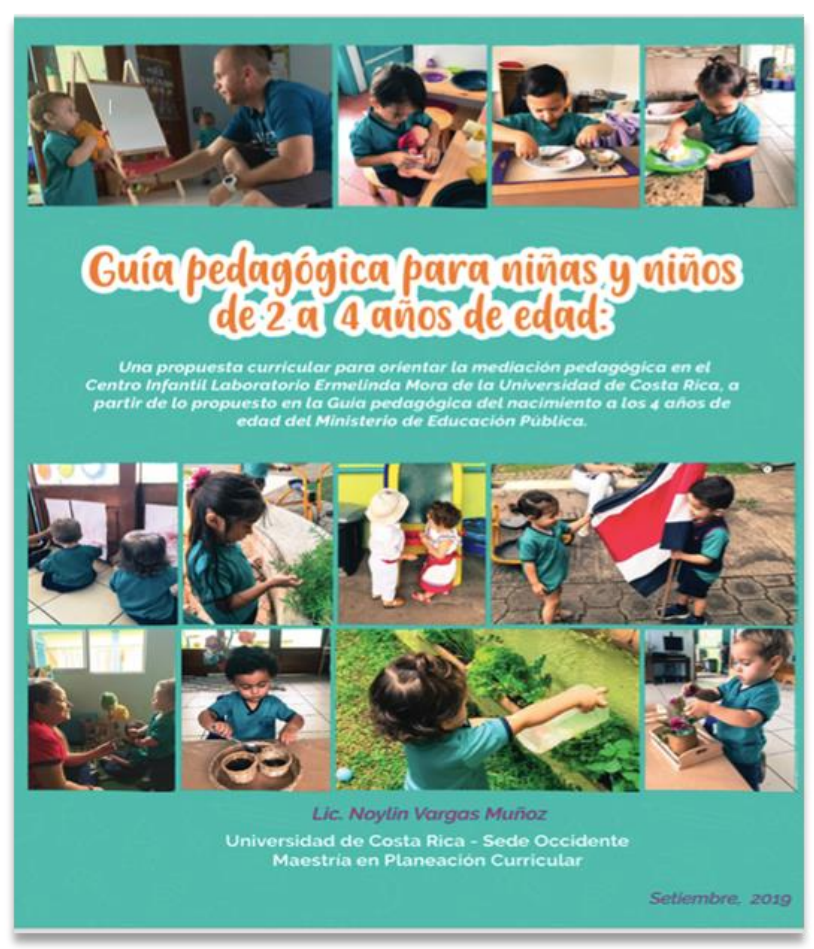

\subsubsection{Instrumentos para la planificación docente desde un modelo de marco abierto}

El documento citado, que es producto del estudio, aporta instrumentos para orientar los procesos de mediación pedagógica de la institución, a partir de lo propuesto por el MEP. Este escenario permite la concatenación entre una realidad específica, previamente conceptualizada, construida con el aporte del personal docente, y un documento oficial para la atención de niñas y niños de 2 a 4 años. 


\section{Figura 2}

\section{Instrumentos presentes en la Guía del CILEM que permiten orientar los procesos de mediación pedagógica desde un modelo de marco abierto}

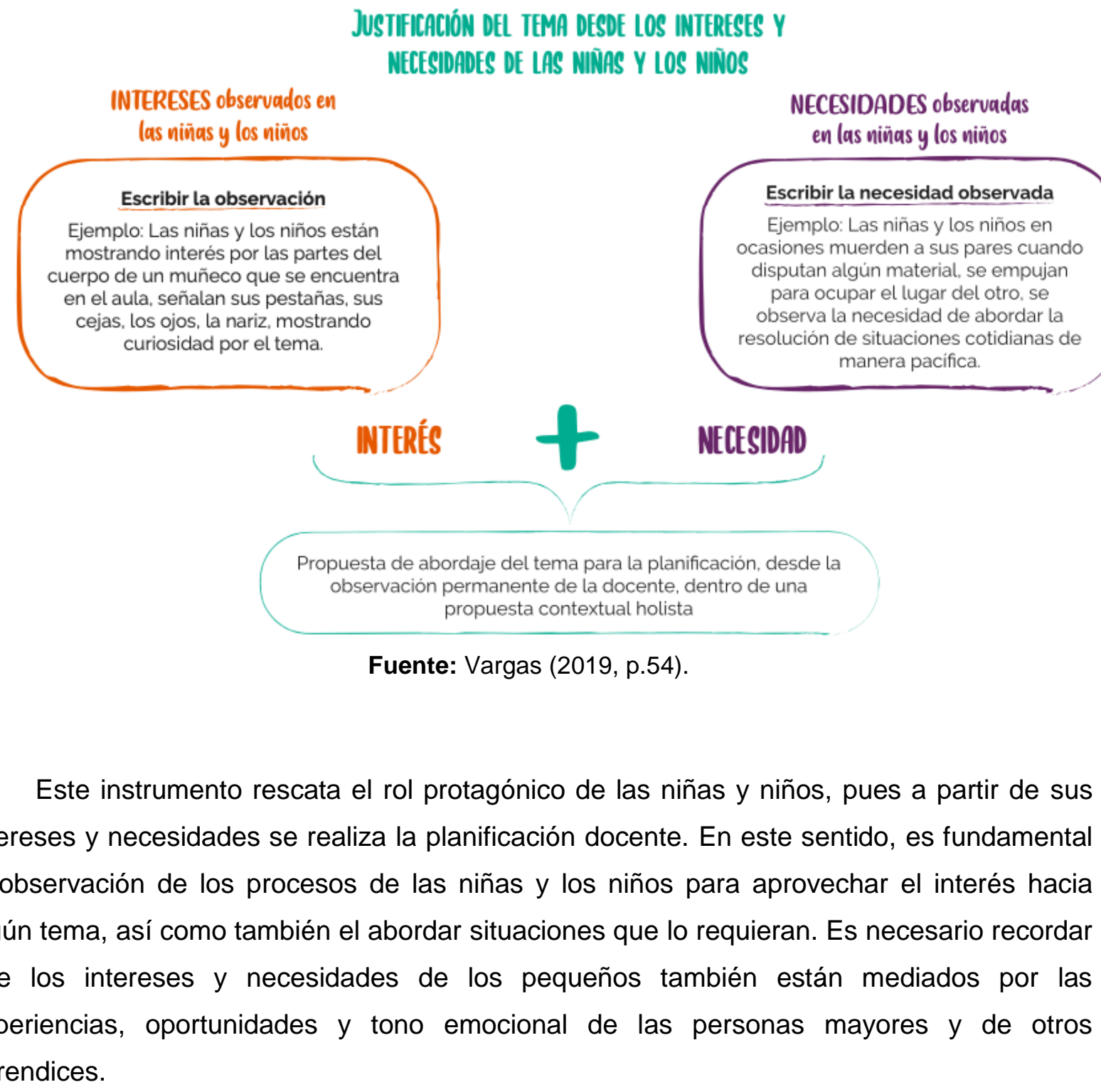




\section{Figura 3}

\section{Instrumento para definir los ámbitos de manera interrelacionada}

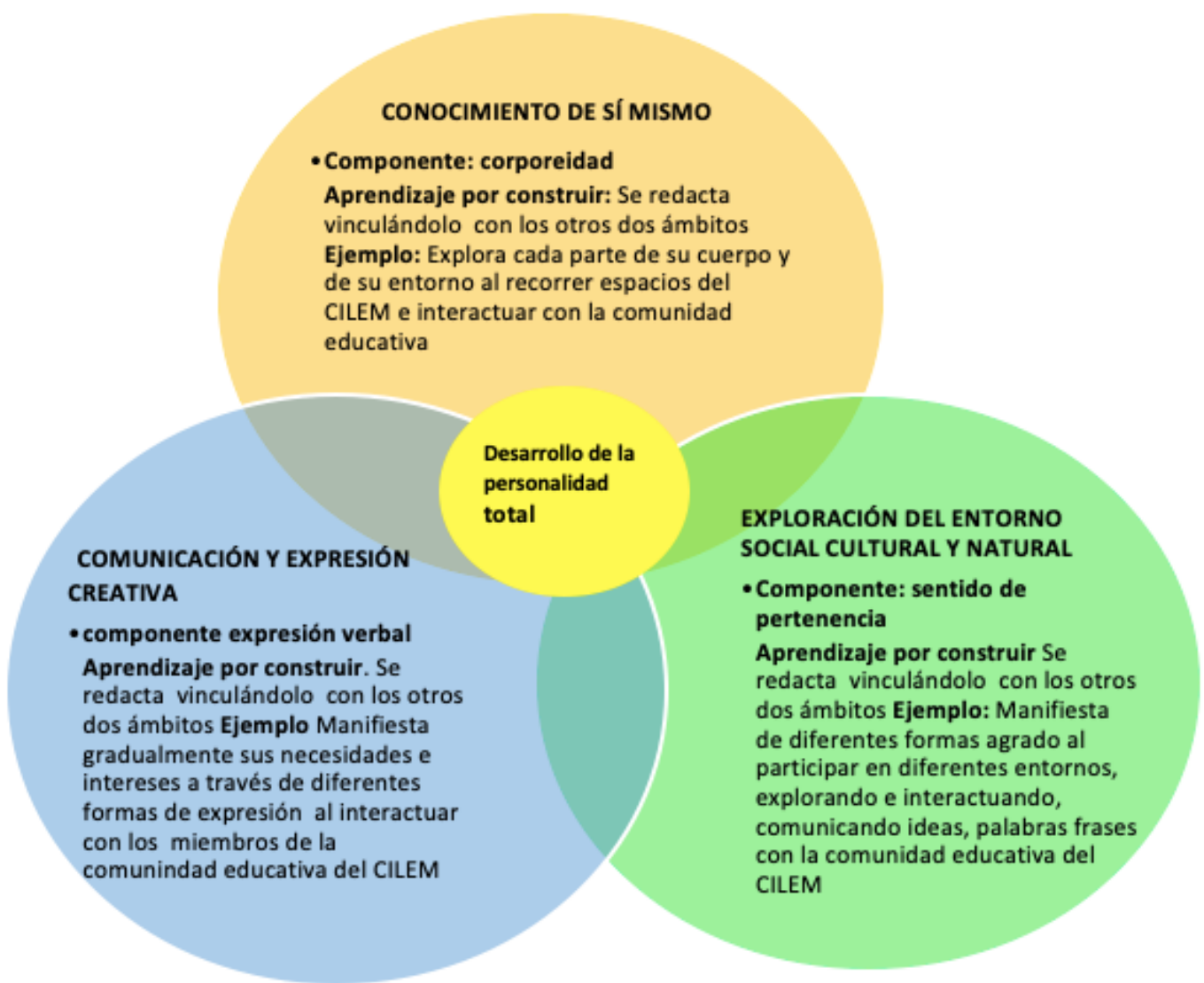

Fuente: Vargas (2019, p.58).

Este instrumento permite al personal docente ver los ámbitos de aprendizaje de manera interrelacionada, tal y como lo propone el modelo educativo de la Institución. El objetivo es favorecer en las niñas y los niños el desarrollo total de su personalidad. Vale rescatar que este concepto era un constructo teórico central en las discusiones de análisis curricular que se implementaron en la institución desde el año 2007. 
Tabla 3

Plantilla de planificación desde una visión holista

\begin{tabular}{|c|c|c|c|}
\hline Componentes & $\begin{array}{l}\text { Aprendizajes por } \\
\text { construir }\end{array}$ & $\begin{array}{l}\text { Estrategias de } \\
\text { mediación }\end{array}$ & $\begin{array}{c}\text { Conducta observable o } \\
\text { indicador }\end{array}$ \\
\hline $\begin{array}{l}\text { Se visibiliza de } \\
\text { manera integral, los } \\
\text { componentes que se } \\
\text { desea abordar en la } \\
\text { planificación. }\end{array}$ & $\begin{array}{l}\text { Se pretende que } \\
\text { los aprendizajes por } \\
\text { construir se asuman } \\
\text { de manera integral, } \\
\text { es decir desde una } \\
\text { mismo aprendizaje } \\
\text { se incluya los tres } \\
\text { ámbitos } \\
\text { contempla la Guía } \\
\text { pedagógica del } \\
M E P \text {. }\end{array}$ & $\begin{array}{lr}\text { Las estrategias } & \text { de } \\
\text { aprendizaje } & \text { se } \\
\text { planifican desde una } \\
\text { visión integral, holista } \\
\text { del proceso educativo. } \\
\text { Por esta razón } \\
\text { contemplan r los } \\
\text { diferentes ámbitos, } \\
\text { componentes r y } \\
\text { aprendizajes. }\end{array}$ & $\begin{array}{l}\text { Para su planificación se } \\
\text { contemplan conductas } \\
\text { observables, esperadas } \\
\text { para la edad de las niñas } \\
\text { y los niños, y sus } \\
\text { periodos sensibles. Se } \\
\text { propone un instrumento } \\
\text { para evaluar el desarrollo } \\
\text { de las niñas y de los } \\
\text { niños, de manera integral. } \\
\text { Lo que permite registrar } \\
\text { los avances en el } \\
\text { proceso. }\end{array}$ \\
\hline
\end{tabular}

Fuente: Vargas (2019, p.59).

Este instrumento permite a las docentes realizar la planificación didáctica de manera interrelacionada, tal y como lo propone el modelo educativo de la institución.

Tabla 4

Instrumento para planificar el ambiente preparado

\begin{tabular}{|c|c|c|c|c|}
\hline Área & Papel docente & $\begin{array}{c}\text { Materiales } \\
\text { disponibles o } \\
\text { experiencias }\end{array}$ & $\begin{array}{c}\text { Rol de la niña y } \\
\text { el niño }\end{array}$ & $\begin{array}{l}\text { Proceso de } \\
\text { desarrollo } \\
\text { presente }\end{array}$ \\
\hline $\begin{array}{l}\text { Ejercicios de } \\
\text { vida práctica }\end{array}$ & $\begin{array}{l}\text { Observar } \\
\text { previamente para } \\
\text { elegir el material. } \\
\text { Proveer lo } \\
\text { necesario. } \\
\text { Realizar } \\
\text { andamiaje. } \\
\text { Dar } \\
\text { acompañamiento. }\end{array}$ & $\begin{array}{l}\text { Ejercicio para } \\
\text { trasvasar agua. } \\
\\
\text { Pichel, vaso } \\
\text { pequeño de } \\
\text { vidrio. }\end{array}$ & $\begin{array}{l}\text { Trasvasar el } \\
\text { agua de un } \\
\text { recipiente al } \\
\text { otro, procurando } \\
\text { no derramar el } \\
\text { agua. } \\
\text { Una vez } \\
\text { finalizado, } \\
\text { recoger el } \\
\text { material, limpiar } \\
\text { y colocarlo } \\
\text { donde } \\
\text { corresponde. }\end{array}$ & $\begin{array}{l}\text { Desarrollo de la } \\
\text { motricidad fina. } \\
\text { Coordinación } \\
\text { viso motora. } \\
\text { Concentración. } \\
\text { Control de error. } \\
\text { Auto gestión. } \\
\text { Gusto por el } \\
\text { aprendizaje. }\end{array}$ \\
\hline
\end{tabular}

Fuente: Vargas (2019, p.55).

Este instrumento orienta a las docentes en la planificación del ambiente preparado y la reflexión del porqué y para qué de lo que se coloca en el espacio de aula. 


\section{Figura 4}

\section{Propuesta de instrumento para involucrar a las familias en el trabajo que se realiza en el aula}

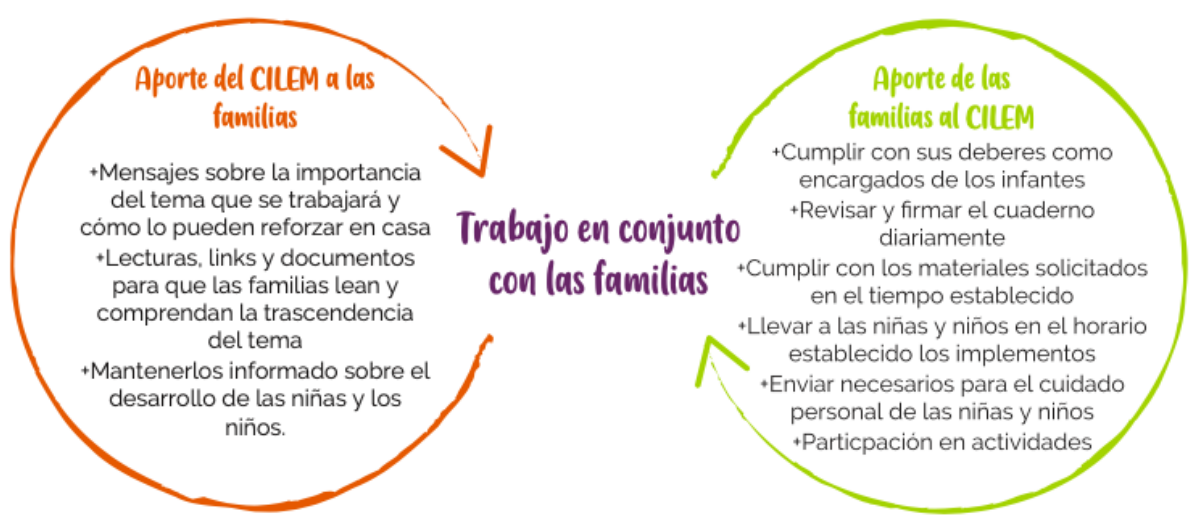

Fuente: Vargas (2019, p.76).

Este instrumento permite incorporar a las familias en la planificación del trabajo docente, se les incluye en una doble dirección, se les informa del trabajo y se les solicita ayuda. 
Tabla 5

Propuesta de instrumento para registrar el avance de las niñas y los niños desde un modelo de marco abierto

Indicadores del desarrollo. Este apartado incluye los indicadores que vienen en la Guía del MEP, adaptados o contextualizados a la realidad del CILEM. Los indicadores pueden ser construidos por las docentes, que contemplen conductas esperadas para la edad de las niñas y los niños. Ejemplo: Realiza movimientos psicomotrices al desplazarse por el CILEM; expresa de diferentes maneras agrado al participar de diferentes entornos del CILEM; manifiesta sus necesidades de manera verbal a diferentes miembros de la comunidad educativa del CILEM.

Conductas por observar para el desarrollo integral. En este apartado se colocan las conductas observables que incluyan de manera integral los indicadores; es decir desde la observación de una conducta, se puede obtener información del desempeño de manera integral. Ejemplo: Se desplaza con estabilidad por el CILEM e interactúa con los miembros de la comunidad educativa con seguridad y confianza.

\begin{tabular}{|c|c|c|c|c|c|}
\hline $\begin{array}{l}\text { Niña } 0 \\
\text { niño }\end{array}$ & $\begin{array}{c}\text { Desempeño en la } \\
\text { semana } 1\end{array}$ & $\begin{array}{c}\text { Desempeño en la } \\
\text { semana } 2\end{array}$ & $\begin{array}{c}\text { Desempeño en la } \\
\text { semana } 3\end{array}$ & $\begin{array}{c}\text { Desempeño en la } \\
\text { semana } 4\end{array}$ & $\begin{array}{l}\text { Observaciones y } \\
\text { recomendaciones }\end{array}$ \\
\hline A & $\begin{array}{l}\text { A partir de lo observado } \\
\text { en la niña o en el niño, se } \\
\text { registra cómo ha sido el } \\
\text { desarrollo en los distintos } \\
\text { momentos del proceso. De } \\
\text { esta manera, se pueden } \\
\text { mencionar actividades } \\
\text { específicas que se han } \\
\text { realizado en la } \\
\text { planificación. Ejemplo: } \\
\text { Durante esta semana A, } \\
\text { muestra estabilidad en sus } \\
\text { movimientos. }\end{array}$ & $\begin{array}{l}\text { De esta manera se puede } \\
\text { contemplar el desempeño } \\
\text { durante el proceso. } \\
\text { Ejemplo: Durante esta } \\
\text { semana, al visitar las } \\
\text { oficinas, el comedor y el } \\
\text { cuarto, de pilas se } \\
\text { observó cómo los } \\
\text { movimientos locomotores } \\
\text { de A mejoraron } \\
\text { notablemente. }\end{array}$ & $\begin{array}{l}\text { Con este instrumento } \\
\text { se evita que la } \\
\text { evaluación se realice } \\
\text { ubicamente al final } \\
\text { del proceso. } \\
\text { Ejemplo: } \\
\text { Al realizar un juego } \\
\text { con los miembros del } \\
\text { personal se observó } \\
\text { cómo A, quiso } \\
\text { participar; } r \quad \text { la } \\
\text { preguntarle si la } \\
\text { actividad era de su } \\
\text { agrado, dijo que sí. }\end{array}$ & $\begin{array}{l}\text { Este instrumento } \\
\text { favorece la toma de } \\
\text { decisiones en el } \\
\text { proceso. } \\
\text { Ejemplo: } \\
\text { Luego de la realización } \\
\text { de las actividades } \\
\text { planificadas, se observó } \\
\text { cómo la motricidad de A } \\
\text { es adecuada para su } \\
\text { edad, pues no presentó } \\
\text { mayor dificultad al } \\
\text { realizarlas. }\end{array}$ & $\begin{array}{l}\text { En este apartado se } \\
\text { registran anotaciones } \\
\text { que permiten } \\
\text { individualizar el } \\
\text { proceso y tomar las } \\
\text { medidas que resulten } \\
\text { pertinentes. } \\
\text { Ejemplo: } \\
\text { Se recomienda } \\
\text { trabajar el apego } \\
\text { seguro en A, para que } \\
\text { se relacione de } \\
\text { manera segura con } \\
\text { otras personas aparte } \\
\text { de su docente. }\end{array}$ \\
\hline
\end{tabular}

Fuente: Vargas (2019, p.74).

Este instrumento permite registrar el desempeño de las niñas y los niños de manera integral, tal y como se plantea en un modelo de marco abierto. Con su aplicación se busca la toma de decisiones de manera pertinente y oportuna. 


\subsection{Resultados convergentes/conclusiones tardías con otros estudios}

En la elaboración de esta propuesta fue pertinente establecer un marco normativo que incluyera aspectos relacionados con lo que establece la legislación en Costa Rica para la atención de las niñas y los niños en estas edades. En este sentido, cabe destacar que durante el desarrollo de este estudio se elaboró, por parte del Patronato Nacional de la Infancia, la Política para la Primera Infancia (2015 - 2020), la cual, aunque al inicio del trabajo no se contempló, pues no existía, posteriormente a su publicación debió incluirse como parte del marco normativo del objeto de estudio.

Así mismo, durante la realización de este estudio, el Ministerio de Educación Pública elaboró un marco curricular para la Primera Infancia. El contenido de este documento debió revisarse con la intención de conocerlo y determinar cómo podía influir en el desarrollo de la propuesta.

En la Guía pedagógica para niños y niñas desde el nacimiento y hasta los 4 años del $M E P$, los ámbitos de aprendizaje se presentan de manera separada, aunque en la fundamentación teórica se señala que los ámbitos se interrelacionan. En este sentido, en la elaboración de esta propuesta se decidió establecer la interrelación que se da entre los diferentes ámbitos, tanto en su representación gráfica como en su implementación.

En el trabajo de análisis de la información se constató que hubo varias categorías en las que convergieron las diferentes fuentes. Algunos ejemplos que ilustran lo anteriormente descrito son los siguientes: cuando se les preguntó a las informantes sobre el papel de las niñas y de los niños en el espacio de aula, tanto las docentes como las directoras y las participantes en el taller de investigación, concordaron en el papel protagónico que tienen las niñas y los niños. Esto hace que las acciones que se planifican y las gestiones que se realizan, giren en torno a la niñez.

El papel del contexto sociocultural es otro aspecto en el que concuerdan las participantes, quienes lo señalaron como la base para la planificación. El contexto contempla aspectos familiares y culturales; esto permite propiciar la construcción de aprendizajes significativos. En este sentido, el lenguaje adquiere un papel muy importante en la socialización y el establecimiento de interacciones con la cultura (Rosa y Rodríguez, 2016 y Patiño, 2007).

Existe unidad de criterios, por parte de las fuentes, con respecto a la necesidad de que se planifiquen estrategias para posibilitar el desarrollo integral de las niñas y de los niños. Se pretende que se contemple el desarrollo motriz y del lenguaje, el desarrollo de habilidades 
cognitivas y de habilidades para la vida; así como estrategias que permitan favorecer el aprecio por el ambiente natural y cultural. De igual manera, manifiestan las docentes, la necesidad de posibilitar experiencias de socialización pertinentes para estas edades.

Las opiniones de las participantes convergen en que la docente es guía en el proceso educativo. Las docentes y personas expertas concuerdan en la importancia del andamiaje o modelaje del uso del material como un medio para lograr que las niñas y los niños construyan el conocimiento por medio de los materiales dispuestos en el espacio de aula.

En cuanto al concepto de niña y niño que se desea formar en el CILEM, se encontraron coincidencias en la importancia de que sean niñas y niños con valores, que tengan seguridad personal, que cuenten con bases emocionales, que, desde su formación individual, construyan valores para la convivencia social.

Al tratarse de una propuesta curricular para orientar la mediación del personal docente que atiende niñas y niños de 2 a 4 años, a partir de lo propuesto en la Guía pedagógica para niñas y niños desde el nacimiento y hasta los 4 años propuesta por el MEP, se contempló, previamente en el estudio, aspectos que permitieran sustentar la información que se recopilara. En este sentido, se plantearon los siguientes temas:

Figura 5

Temas que fueron abordados en el fundamento teórico del estudio

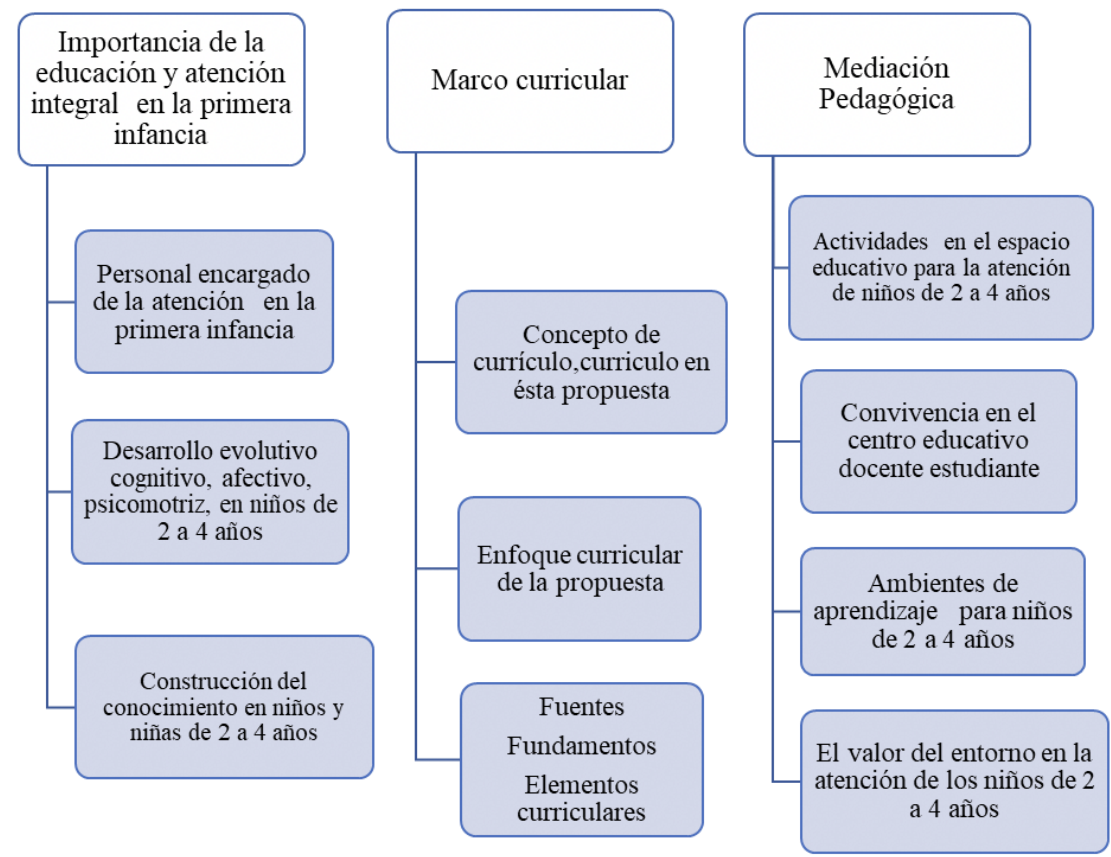

Fuente: Vargas (2019, p.10). 
El sustento teórico citado permitió fundamentar el estudio, no representó ninguna contraposición con las categorías emergentes. No obstante, resultó necesario indagar sobre algunas categorías que emergieron del análisis de la información, como por ejemplo: a) El concepto de ambiente preparado. b) Habilidades para la vida. c) Área de vida práctica. De igual manera, se debió reforzar y profundizar en algunos temas que se contemplaron desde el inicio, como una manera de darle mayor sustento a la investigación.

\subsection{Hallazgos de la investigación}

El principal hallazgo de esta investigación está relacionado con el concepto de evaluación que se emplea en el CILEM.

\subsubsection{Evaluación en un modelo de marco abierto}

Dentro de los procesos de mediación pedagógica, la evaluación que se emplea depende del modelo educativo que se aplica. Al registrar los avances y el desempeño de las niñas y los niños se busca determinar qué tanto se han alcanzado los objetivos propuestos, con la intención de tomar decisiones de manera oportuna.

En esta institución el concepto de evaluación trasciende los aspectos referidos al aprendizaje de las niñas y de los niños, por una parte, abarca la valoración del ambiente existencial desde la criticidad de la figura docente para propiciar ambientes seguros, con nivel de reto, acordes a la edad, con ejercicios de vida práctica que posibiliten el acercamiento al entorno natural y cultural. Por otra parte, incluye las interacciones que se dan y la asertividad de la relación docente estudiante, en los procesos de contención emocional que influyen en la comunicación afectiva y el proceso enseñanza aprendizaje.

El concepto de evaluación en el CILEM se sustenta en el establecimiento de habilidades esperadas para la edad, en los periodos sensibles y en los indicadores que conlleva la toma de decisiones en beneficio del desarrollo integral de las niñas y de los niños. Para esto se utilizan instrumentos como listas de cotejo, registros anecdóticos, crónicas, entre otras. Cabe resaltar que en la Institución se pretende que la evaluación trascienda el trabajo con las niñas y los niños e incluya la intención de decodificar el ambiente físico existencial. Lo anterior se realiza con el objetivo de reflexionar acerca de la función que cumplen los diferentes materiales que se encuentran en el espacio de aula y su congruencia con lo que establece un modelo de marco abierto. 
En este sentido, el papel docente es fundamental como reflexivo de su práctica docente y el por qué de lo dispuesto en el ambiente. El personal docente, en su reflexión constante del ambiente, con su compromiso y creatividad, buscan mejorar lo dispuesto en el aula para propiciar que los materiales sean pertinentes, atractivos, inclusivos, retadores y que promuevan el desarrollo de habilidades para la vida.

En el CILEM, se pretende que se evalúe el ambiente existencial y el papel docente como quien facilita las experiencias para las infantes y los infantes, además del desempeño de las niñas y de los niños de manera integral. La evaluación se concibe como la oportunidad de realizar mejoras, lo que incluye a los diferentes miembros del proceso educativo.

La evaluación en el CILEM se implementa de la siguiente manera: a) ambiente existencial; b) pertinencia de los materiales y recursos, valoración de la pertinencia de cambiar, enriquecer, lo dispuesto en el ambiente acorde con el modelo de marco abierto; c) desempeño docente; d) seguimiento de la la práctica docente, actitud reflexiva de auto mejoramiento, capacitación en modelos de marco abierto, estrategias de auto cuidado; e) desarrollo de las niñas y los niños; f) indicadores acorde con los aprendizajes por construir: conductas esperadas para la edad - periodos sensibles - observación constante del desempeño de los infantes de manera integral.

Precisamente la incorporación de estas categorías que trascienden un modelo mecanicista educativo, permite corroborar el impacto que se puede generar con procesos de discusión y reflexión en equipos interdisciplinarios sostenidos en el tiempo, ya que van generando cambios sistémicos que pueden ser plasmados no solo en los currículos sino en los quehaceres y vivencias.

\section{Conclusiones}

A continuación, se exponen las principales conclusiones a las que se llegó en el estudio, así como las recomendaciones que pueden servir de guía para otras instituciones que requieran realizar propuestas en torno a la mediación pedagógica.

\subsection{Mediación pedagógica en la educación inicial desde un modelo de marco abierto}

a) El papel docente ha tenido cambios significativos, producto de una disposición al diálogo y procesos investigativos. Estos procesos de investigación han venido a mejorar las 
mediaciones que se realizan con las niñas y con los niños. Sin embargo, se reconoce la necesidad de seguir orientando la labor docente ante los cambios y las demandas históricas para que esta resulte altamente congruente con el modelo curricular.

b) Las docentes tienen claridad de su papel de guías y de mediadoras de aprendizajes en las niñas y en los niños, ellas reconocen la necesidad de reflexionar de manera sistemática y constante acerca del accionar en el aula como parte del trabajo que realizan.

c) Se incorpora, dentro del papel docente, el concepto de ambiente preparado, zona de desarrollo próximo y andamiaje como aspectos importantes dentro de los procesos de mediación pedagógica que se realizan en el CILEM.

d) Es necesario establecer con claridad, desde la teoría, qué se espera de la figura docente como quien facilita los procesos, según la metodología empleada en el CILEM, para que realmente haya claridad conceptual y se refleje en las mediaciones que realizan.

\subsection{Concepto de niñez que se desea formar en el CILEM}

a) El concepto de niña o niño que se busca fomentar en el CILEM incluye el desarrollo de personas con habilidades para la vida, que tengan formación en valores y bases emocionales sólidas que les permitan desenvolverse con autogestión y autocontrol.

b) Personas críticas, analíticas, exploradoras, que tengan una visión holista del mundo, respetuosas de la herencia cultural y con amor por toda forma de vida, que tengan herramientas para desenvolverse socialmente de manera asertiva.

\subsection{Actividades que potencian el desarrollo cognitivo}

a) El ambiente preparado es fundamental dentro del trabajo que se realiza en el CILEM. Es visto como un medio por el cual se posibilita la construcción de conocimientos desde la interacción social.

b) Se debe propiciar, en el ambiente preparado, experiencias para que las niñas y los niños construyan el conocimiento.

\subsection{Relación entre la interacción social y la construcción del conocimiento}

a) Dentro del CILEM, las interacciones que se dan a lo interno de los salones de clases se establecen a partir de un modelo educativo flexible, lo que facilita la socialización y construcción del conocimiento desde lo personal y desde lo grupal o colectivo. 
b) La labor docente es la de mediar, facilitar, y las niñas y los niños tienen un papel protagónico. Premisa: En los modelos flexibles, las niñas y los niños establecen relaciones, y se da mayormente la construcción de conocimientos significativos. En los modelos cerrados, la docente o el docente tiene el control y hay menos interacciones; esto influye en los procesos de construcción de conocimientos.

\subsection{Nuevos temas que surgieron del estudio}

A partir de la realización de este estudio podrían generarse nuevos procesos de investigación en aquellas instituciones que atienden niñas y niños menores de 4 años, con metodológías de trabajo cuyo énfasis no es el ámbito educativo.

La contextualización de la Guía pedagógica para niños y niñas desde el nacimiento y hasta los 4 años elaborada por el MEP, puede constituir un insumo importante en la formación universitaria de futuros profesionales que se forman el campo de la educación inicial.

Debido a que este estudio está enfatizado en la mediación pedagógica, específicamente para las niñas y los niños de 2 a 4 años, un estudio posterior puede abarcar a la niñez con edades comprendidas entre los 8 meses y hasta los 2 años de edad.

Es importante destacar que este trabajo puede generar un estudio longitudinal, con la intención de sistematizar las experiencias a partir de la aplicación de la Guía pedagógica del CILEM y determinar logros obtenidos y oportunidades de mejora; esto permitiría observar procesos de cambio a lo largo del tiempo.

\subsection{Nuevas preguntas de investigación}

Entre las principales preguntas de investigación que pueden surgir a partir de la realización de esta propuesta se contemplan las siguientes:

¿Cómo aplicar la Guía Pedagógica para niños y niñas desde el nacimiento y hasta los 4 años elaborada por el MEP a la propuesta educativa de los Hogares Comunitarios en Costa Rica?

¿Con qué herramientas pedagógicas cuenta una madre comunitaria para la implementación de la Guía pedagógica para niños y niñas desde el nacimiento y hasta los 4 años elaborada por el del MEP?

¿Qué herramientas tienen las estudiantes universitarias de educación inicial para la aplicación de la Guía pedagógica para niños y niñas del nacimiento a los 4 años del MEP? 
¿Qué estrategias de seguimiento y/o evaluación contempla el MEP para mejorar la implementación de la Guía pedagógica para niños y niñas del nacimiento a los 4 años?

\subsection{Recomendaciones}

El estudio recomienda varios aspectos relevantes en la construcción de una propuesta curricular. Incluye aportes a instancias docentes y administrativas con el propósito de fortalecer mejoras en la atención de la primera infancia que faciliten adaptar la Guía pedagógica para niños y niñas desde el nacimiento y hasta los 4 años del MEP a una realidad específica.

\subsubsection{Contexto sociocultural}

1. La Guía pedagógica para niños y niñas desde el nacimiento y hasta los 4 años del MEP se debe adaptar a la realidad propia del CILEM, procurando tomar en cuenta características propias del contexto local, lo cultural, costumbres y tradiciones.

2. Definir el fundamento sociocultural de la propuesta.

3. Definir el papel del entorno cultural, cómo este se materializa en experiencias que aportan en el desarrollo de las niñas y de los niños.

4. Incluir el ambiente cultural como eje transversal.

\subsubsection{Mediación pedagógica}

5. Definir el concepto de mediación docente desde un modelo de marco abierto.

6. Proceso de inducción y sensibilización en el personal docente para lograr puntos de equilibrio emocionales en las niñas y los niños que permitan enfrentar procesos de adaptación y socialización.

7. Hacer una definición de currículo propia de la propuesta con base en las experiencias cotidianas pero respondiendo a un marco mayor los fines de la educación costarricense, realizar sensibilización del personal sobre el porqué de las reacciones que se realizan.

8. En el formato de planificación, incluir una casilla de ambiente preparado para describir o, al menos, mencionar cómo este se relaciona con el trabajo que se realiza y los aprendizajes por construir.

9. Establecer, con claridad, el papel docente dentro de este modelo de marco abierto para lograr niveles de congruencia en las acciones que se realizan a nivel institucional.

10. Se recomiendan procesos de actualización docente en modelos de marco abierto. 
11. Construir un instrumento que permita evaluar el ambiente educativo, a partir de lo dispuesto en el instrumento arco iris de oportunidades que ya existe.

12. Se recomienda tener claridad de que el rol activo y protagónico de las niñas y de los niños nace de la figura docente, quien posibilita, en todo momento, que los infantes construyan aprendizajes.

13. Definir el concepto de niña y de niño para la propuesta.

14. Definir conductas esperables para la edad, que permitan orientar los aprendizajes por construir y las estrategias didácticas que se planifican.

15. Incluir, en la propuesta, los periodos sensitivos desde la pedagogía Montessori para construir aprendizajes acordes con los intereses y necesidades de las niñas y de los niños.

16. Realizar ecoanálisis del ambiente existencial problematizando acerca de la pertinencia de lo dispuesto en el ambiente.

\subsubsection{Marco pedagógico institucional}

17. Es importante definir características personales y profesionales deseables en el personal que atiende esta población, así como también, claridad sobre sus funciones para facilitar el seguimiento al desempeño docente.

18. Se recomienda elaborar, dentro de la propuesta, un marco filosófico como un instrumento orientador del personal docente de la institución.

19. Crear, en la propuesta, un glosario donde se incluya terminología específica, de la práctica docente, desde un modelo de marco abierto.

20. Establecer con claridad lo que pretende un modelo de marco abierto como referente filosófico y desde ahí llevar a la práctica acciones en pro del desarrollo integral.

21. Definir el papel de los elementos y fuentes curriculares para la propuesta.

22. Definir el enfoque curricular de la propuesta.

23. Incluir en la plantilla de planificación la manera de vincular a las familias en el trabajo.

\section{Referencias}

Ausubel, David. (1983). Teoría del aprendizaje significativo. Fascículos de CEIF, 1, (1-10). Recuperado de https://www.academia.edu/10435788/TEOR\%C3\%8DA TEORIA DEL APRENDIZAJE SIGNIFICATIVO 
Álvarez, Juan Luis. (2003). Cómo hacer investigación cualitativa. Fundamentos y metodología. México: Paidós.

Carvajal, Darling., Castro, María Antonieta., Molina, Kimberly., Rodríguez, Indira., Rosada, Laizet. y Vargas, Francini. (2015). Participación cultural plena y su mediación psicopedagógica en situaciones sociales de desarrollo en un centro infantil universitario, desde la investigación-acción (Seminario de Trabajos finales de Graduación para acceder al título de Licenciatura en Psicología). Universidad de Costa Rica, San José, Costa Rica.

Castillo, lleana. y Castillo, Rocío. (2016). Mediación pedagógica para la primera infancia reflexiones desde el sentir y el pensar. San José: Costa Rica. EUNED.

Chavarría, María Celina. y Orozco, Cynthia (2006a). Ecoanálisis como puerta de entrada a la decodificación de lo cotidiano: Hacia una educación posible. Actualidades Investigativas en Educación, 6(3), 1-35. DOI 10.15517/aie.v6i3.9231

Chavarría, María Celina. y Orozco, Cynthia. (2006b). Arco iris DE OPORTUNIDADES (A/O)": Un instrumento holista para la evaluación de contextos de aprendizaje en centros infantiles (Manuscrito no publicado). San José, C.R.: Universidad de Costa Rica: Instituto de Investigaciones Psicológicas.

Chavarría, María Celina. y Orozco, Cynthia. (2009). Situaciones sociales de desarrolloaprendizaje: Diálogos y confirmaciones desde la investigación-acción en un CINAI costarricense. Actualidades Investigativas de la Educación, 9(Número Especial), 137. DOI 10.15517/aie.v9i4.9511

Chavarría, María Celina. y Pérez, Marianela. (1995). El reto de la educación preescolar en una sociedad cambiante. San José, Costa Rica: Editorial de la Universidad de Costa Rica.

Chavarría, María Celina; Obando, Milagro; y Orozco, Cynthia. (2009). Ecoanálisis y decodificación de lo cotidiano en las prácticas formativas en los programas de atención a la niñez en los centros infantiles universitarios (Informe final. Proyectos № 723-A4326 del Instituto de Investigaciones Psicológicas y Proyecto No. 724-A7-102 del Instituto de Investigaciones en Educación). San José: Universidad de Costa Rica.

Chavarría, María Celina., Orozco, Cynthia., Chacón, Yamileth. y Ovares, Mabel. (2000a). Aciertos y vicisitudes en la búsqueda de valores hacia la paz y el desarrollo sostenible: La decodificación de lo cotidiano como herramienta teórico-práctica. Revista $\begin{array}{llll}\text { Costarricense de Psicología, 16(31), } & 23-45 . & \text { DOI }\end{array}$ http://www.kerwa.ucr.ac.cr/handle/10669/779

Chavarría, María. Celina., Orozco, Cynthia. y Vargas, Isaac. (2016). La educación como vivencia, diseño y escenario histórico-cultural: Tres aproximaciones hacia la decodificación y transformación del currículo oculto en educación inicial. En Wanda Rodríguez Arocho, Maurizia D’Antoni y Victoria González (Eds.), Vygotski y su legado en la investigación en América Latina (pp. 51-75). San José, C.R.: Universidad de Costa Rica: INIE. 
Contreras, lleana. (junio, 2010). De la enseñanza a la mediación pedagógica ¿Cambio de paradigma 0 cambio de nombre? Revista Educación, 19(2), 5-15. DOI 10.15517/REVEDU.V19I2.8452

Ministerio de Educación Pública. (2017). Guía Pedagógica del nacimiento a los 4 años. San José, Costa Rica.

Montessori, Mario. (1991). La educación para el desarrollo humano. D.F, México: Ed. Diana.

Orozco, Cynthia. (2007). El ecoanálisis como mediación psicopedagógica: experiencia en el Centro Infantil Ermelinda Mora. Revista electrónica Actualidades Educativas en Investigación, 7(1). DOI 10.15517/aie.v7i1.9244

Orozco, Cynthia.; Durán, Maricel.; Fernández, Evelyn.; Hidalgo, Sarita., Quintanilla, Hannia.; y Ramírez, Eva. (2014). Acercamiento crítico al holismo en la educación inicial: Una discusión metodológica. Revista Diálogos, 15(Especial Región Occidental de Costa Rica). Recupeado https://revistas.ucr.ac.cr/index.php/dialogos/article/view/16308/15810

Patiño, Luceli. (2007). Aportes del enfoque histórico cultural para la enseñanza. Educación y Educadores, 10(1), 53-60. Recuperado de https://www.redalyc.org/pdf/834/83410106.pdf

Patronato Nacional de la Infancia. (2015). Política para la primera Infancia, 2015-2010. San José, Costa Rica: Ministerio de Educación Pública.

Peralta, María Victoria. y Fujimoto, Gabriela. (1998). La atención integral de la primera infancia en América Latina: ejes centrales y los desafíos para el siglo XXI. Santiago de Chile: Organización de Estados Americanos.

Quattrocchi, Silvana. (1999). Un ser humano. La importancia de los primeros tres años de vida. Santiago, Chile: Editorial Cuatro Vientos.

Rodríguez, Wanda. (2010). El concepto de calidad educativa: una mirada crítica desde el enfoque históricocultural. Revista Actualidades Investigativas en Educación, 10(1), 128. DOI $\underline{10.15517 / a i e . v 10 i 1.10088}$

Rosa, Nieves. y Rodríguez, Wanda. (2016). Un modelo de educación en clave Vigotskiana: estudio piloto del desarrollo socioemocional de pre-escolares con el currículo "Key to Learning". Revista Puertorriqueña de psicología, 27(2), 334-352. Recuperado de https://www.redalyc.org/pdf/2332/233247620010.pdf

Vargas, Isaac.; González, Pamela.; Chavarría, Edison.; Valverde, Zaida.; Jiménez, Alicia. y Quirós, Sol. (2014). Enriquecimiento de actividades hacia una cultura de solidaridad y paz en un centro infantil. (Seminario de graduación para optar al título de Licenciatura en Psicología). Universidad de Costa Rica, San José, Costa Rica.

Vargas, Noyle. (2019). Propuesta Curricular de contextualización para la mediación pedagógica del personal docente que atiende niñas y niños de 2 a 4 años en el Centro Infantil Laboratorio Ermelinda Mora (Tesis de Maestría). Universidad de Costa Rica, San José, Costa Rica. 
Revista indizada en
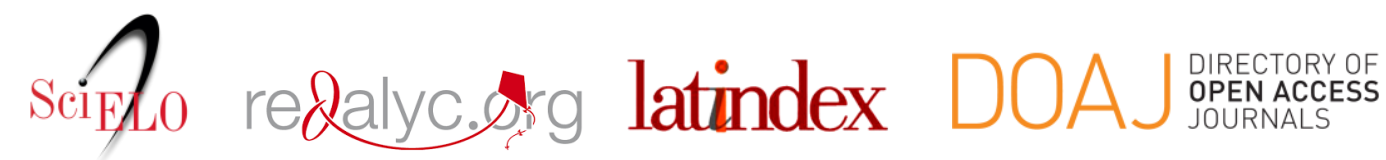

Distribuida en las bases de datos:

- Dialnet

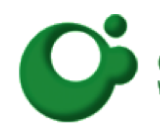
SHERPA/RøMEO

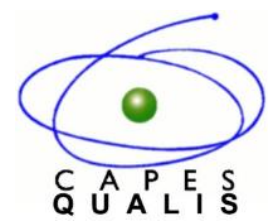

MIAR 